\title{
Influences on Transfer Effectiveness: An Exploratory Study of Headquarters Transfer of Capabilities to Subunits in the MNC
}

Olof Lindahl

Ph.D. awarded by Uppsala University, Sweden (May 2015)

\section{BIG Question:}

\section{"Why does the effectiveness of headquarters-driven transfers of capabilities vary between subunits in the MNC?"}

\section{Introduction}

This dissertation explores the influences on effectiveness in headquarters-subunit transfer of capabilities, a phenomenon that has been the focus of little empirical investigation in cases where headquarters involves itself as the active sender. Using an exploratory multiple-case study, it investigates influences on effectiveness in headquarters' transfer of the same capability to 18 innovation projects located in Asia, Europe and the US. On the basis of 100 interviews with headquarters managers responsible for the transfers, and innovation project teams that receive the transferred capability, a number of novel influences to transfer effectiveness are identified and unpacked. Key findings include the importance of headquarters' transfer management efforts in influencing the ability and commitment of receiving project teams to adopt the transferred capability. The findings also show how the receivers of the transfers were not limited to the innovation projects, but also included internal and external supporting networks of engineering firms and functions that were found to critically influence transfer effectiveness. On the back of these findings, this dissertation suggests an important yet neglected role of headquarters in actively managing transfers of capabilities to subunits, and adds an interesting alternative to viewing transfers as occurring in isolated sender-receiver dyads by suggesting that the receiver may sometimes be a network.

\section{Background}

Empirically, this study explores the attempts by headquarters to standardize the ways in which subunits innovate in the multinational corporation (MNC) by transferring common capabilities to subunit innovation projects. This standardization aims to establish commonalities that allow for increased cooperation and coordination between subsidiary innovation projects to increase the competitiveness of the MNC.

Initiatives such as these become relevant as MNCs add new subunits that serve different geographical and product markets, and their inter- nal organization gradually becomes more complex, i.e., more dispersed and differentiated. Although such complexity can be advantageous for an MNC, it can also make coordination of, and cooperation between, subunits difficult. Headquarters has an important role to play in reducing this complexity within the MNC, and one way of doing so (in relation to innovation projects) is by transferring common capabilities to subunits. However, capabilities are particularly complicated to transfer effectively (i.e., to fully implement), and an increased understanding of the determinants of effectiveness in transfers of capabilities is much needed.

The importance of acknowledging the differences between headquarters-subunit, and subunit-subunit, transfers in MNCs, such as the authority and motivation of the sender, have been much argued (Gupta \& Govindarajan, 2000; Mudambi, 2002; Tran et al., 2010). Despite this, little in-depth research has been conducted to gain a richer understanding of the determinants of effectiveness in headquarters-driven transfers of capabilities to subunits in the complex organizational environment of MNCs. In the research that has been done the role of headquarters has either been that of supervising transfers between subunits (e.g. Ciabuschi et al., 2011; Yamin et al., 2011) or as a sender where there is nothing to indicate that the single most powerful unit in the MNC is involved (e.g., Kostova \& Roth, 2002; Minbaeva, 2007; Jensen \& Szulanski, 2007). While it is hard to say, it is possible that in the latter case headquarters is not found to be a unique kind of sender because the measurements used do not allow capturing this. However, empirical research on strategy implementation lend support to arguments that headquarters-subunit transfers are different by identifying how headquarters may affect subunit propensity to implement (Schleimer et al., 2014; Schleimer \& Pedersen, 2014). Together with the theoretical reasoning of Gupta and Govindarajan (2000) and Mudambi (2002), these empirical findings suggest a gap in the literature concerning influences on effectiveness in headquarters-driven transfers of capabilities to subunits in the MNC. This study argues that an exploratory investigation to unpack how the complex organizational context of MNCs may influence effectiveness in headquarters-driven transfers of capabilities to subunits is valuable for attaining in-depth understanding of this phenomenon. It thereby explores why the effectiveness of headquarters-driven transfers of capabilities varies between subunits in the MNC. 


\section{Summary of Studies}

Headquarters varying success in transferring a common capability across its globally dispersed subunits makes VCE-a global industrial firm - an excellent laboratory for an in-depth multiple-case study of transfer effectiveness (Eisenhardt, 1989; Eisenhardt \& Graebner, 2007). This study is based on 100 personal interviews on two organizational levels; with managers at headquarters responsible for transfers on the one hand, and with members of 18 receiving innovation projects on the other. These projects were based at six subunits in Asia, Europe, and the US and all received the same capability transferred by headquarters. Innovation projects were sampled in equal numbers of high and low effectiveness transfer cases while also holding most project characteristics constant to be better able to compare the projects in exploring the determinants of transfer effectiveness. The transcribed interviews were inductively coded and then compared and contrasted first within projects, then between projects of the same high or low transfer effectiveness. Finally, the high-effectiveness group was compared to the low-effectiveness group of cases to identify differences that could be linked to the resulting transfer effectiveness. By contrasting the transfer situation facing nine innovation projects with high transfer effectiveness with that facing nine innovation projects with low transfer effectiveness, the findings of this study reveal a number of influences to transfer effectiveness not previously highlighted in existing research. Two of these influences to transfer effectiveness will be elaborated on below.

First, the study identifies how the active transfer management efforts of headquarters, in terms of providing transfer training and support that aimed to fulfill the corresponding needs in the projects, were seen as critically important by both headquarters and the receiving project teams. However, providing the needed training and support to the receiving organizations was also found to be particularly challenging for headquarters to achieve. The transfer management activities of headquarters were found influential in affecting the ability of projects to implement the transferred capability in several ways. However, the problems that headquarters sometimes faced in providing the right training and support also negatively affected the receiving projects' commitment to implement, suggesting a not only important but also sensitive role of headquarters in managing transfers. More specifically, the difficulty of providing the right kind of training, in the right amount, and at the right time to best match the projects needs were found to be a challenge. Moreover, to supply the right kind of support, be it in the form of capability experts, additional funds to cover costly side effects of the transfer, or leadership to help resolve conflicts caused by the new capability, was also found to be a challenge for headquarters in several cases.

Second, highlighting the importance of the recipient context to transfer effectiveness, this study identifies the "fit" between the requirements of the new capability on the one hand, and the ability and capacity of the innovation projects' internal and external supporting engineering networks to strongly influence transfer effectiveness. The reliance of receiving innovation projects on internal and external functions complicated the transfer as the sources of possible mismatches between the requirements of the new capability on the one hand, and the corresponding ability of the receiving organization on the other. For example, the capacity of the supporting networks in terms of their scale and scope of expertise, as well as their ability to coordinate their dispersed functions in accordance with the new capability, were found to negatively influence transfer effectiveness. This, in turn, varied between projects and was found to be particularly difficult for headquarters to handle in managing the transfer.

\section{Implications for Theory and Managerial Practice}

The exploratory research design has allowed this study to contribute to theory and managerial practice with novel insights into influences on effectiveness in headquarters transfer of capabilities to subunits in the MNC. These contributions pertain to: (1) the role of headquarters in actively managing transfers and (2) the finding that the receiver sometimes is not so much the targeted innovation project in isolation as an interdependent network of internal and external functions. The findings of this study have important theoretical implications for the standardization of innovation activities in firms with a global footprint. Beyond the field of international business, the influences on transfer effectiveness identified in this study are argued to be relevant for all multi-business organizations seeking to establish common capabilities among innovating subunits. In exploring influences on effectiveness in headquarters-driven transfers of capabilities to subunits, this study answers the call for research by van Wijk et al. (2008) who found that the effects of headquarters on the outcome of transfers has scarcely been covered in extant literature. The finding of this study make the following contributions to international business theory and managerial practice.

First, this study contributes to theory by introducing the active role of headquarters as a facilitator of the transfer, and does so in an organizational setting that has been found to be particularly complex. This suggests that the role of headquarters in managing transfers can support transfer effectiveness, but also challenge it if the transfer management effort results in lowered recipient commitment as the difficulties facing headquarters in managing the transfer frustrates also the attempts of the receiving units. This indicates a need for further problematizing the active role of headquarters in managing transfer of capabilities to subunits to an extent that is currently absent in the literature. It more specifically suggests that headquarters may not only enjoy advantages derived from its hierarchical position, but also may suffer disadvantages stemming from this position. Such disadvantages may, for example, result from headquarters not being part of, and thereby sometimes less familiar with, the local operational environment of distant subunits. This study argues that understanding the role of headquarters in managing capability transfers in MNCs requires taking into account the special conditions that apply to transfer processes where the sender is both highly motivated and a unit of great authority in the corporation.

From a managerial standpoint, the difficulty of accurately assessing the need for transfer training and support in the receiving projects can be 
seen as requiring headquarters to predict what challenges projects and their supporting networks are likely to face in the transfers and to take measures to help them overcome these challenges. This will require the involvement of key people who are knowledgeable about both the general capability being transferred and the specific organizational contexts it is transferred to. This role of headquarters in managing transfers is found critically important to transfer effectiveness also in terms of influencing recipient commitment, suggesting that the actions of headquarters are closely followed by subunits.

A second implication of this study concerns how research on effectiveness in headquarters-subunit transfers of capabilities has traditionally almost exclusively focused on the dyad of a sender and a receiver. This is an intuitive focus, considering how the phenomenon is characterized as comprising one sending and one receiving unit. However, this study indicates that supporting networks can influence transfers in and of themselves. The findings of this study thereby suggest that it is necessary to question the common tendency in research on effectiveness in headquarters-subunit transfer of capabilities to focus on the sender-receiver dyad. It moreover implies that influences on effectiveness may emanate not only from outside the transfer process, but also from outside the organizational boundaries of the MNC. The managerial challenges posed by the findings of how internal and external networks can influence transfer effectiveness blurs the boundaries of capability transfers. This, in turn, makes the active role of headquarters as a sender more complex as it requires taking the extent to which supporting networks are involved with the capability, and whether they can provide what is needed to handle the requirements of this involvement, into account at an early stage.

In conclusion the managerial implications of the findings of this study revolve around the increased necessity of an active headquarters sender to forecast what the main challenges to a transfer's effectiveness are likely to be. This involves how different challenges can be expected to affect the receiving projects as well as their internal and external supporting functions. It furthermore involves what headquarters can do to overcome these challenges by providing training and support. However, in performing an active role, headquarters need also to be aware that the credibility of the transfer and the commitment of the organization may hinge on how this role is conducted and perceived.

Regarding the theoretical implications, the findings of this exploratory study together suggest an alternative perspective on effectiveness in headquarters-subunit transfers of capabilities. This perspective views transfers not as isolated transfers of general capabilities in simple sender-receiver dyads, but as transfers of specific capabilities with specific requirements between active, authoritative senders and complex recipient systems - the boundaries of which essentially rely on the capability being transferred. This perspective on transfer effectiveness in MNCs provides considerable richness to theoretical understanding of transfer effectiveness, and in doing so, opens up several interesting avenues for future research.

\section{References}

Ciabuschi, F., Forsgren, M., \& Martín, O.M. 2011. Rationality vs ignorance: The role of MNE headquarters in subsidiaries' innovation processes. Journal of International Business Studies, 42(7): 958-970.

Eisenhardt, K. 1989. Building Theories from Case Study Research. Academy of Management Review, 14(4): 532-550.

Eisenhardt, K., \& Graebner, M. 2007. Theory Building from Cases: Opportunities and Challenges. Academy of Management Journal, 50(1): 25-32.

Gupta, A., \& Govindarajan, V. 2000. Knowledge Flows within Multinational Corporations. Strategic Management Journal, 21(4): 473-496.

Jensen, R. J., \& Szulanski, G. 2007. Template Use and the Effectiveness of Knowledge Transfer. Management Science, 53(11): 1716-1730.

Kostova, T., \& Roth, K. 2002. Adoption of an Organizational Practice by Subsidiaries of Multinational Corporations: Institutional and Relational Effects. Academy of Management Journal, 45(1): 215-233.

Minbaeva, D.B. 2007. Knowledge transfer in multinational corporations. Management International Review, 47(4): 567-593.

Mudambi, R. 2002. Knowledge management in multinational firms. Journal of International Management, 8(1): 1-9.

Schleimer, C. S., \& Pedersen, T. 2014. The effects of MNC parent effort and social structure on subsidiary absorptive capacity. Journal of International Business Studies, 45(3): 303-320.

Schleimer, C. S., Coote, L. V., \& Riege, A. 2014. The effects of MNC parent effort and social structure on subsidiary absorptive capacity. Journal of Business Research, 67(3): 307-315.

Tran, Y., Mahnke, V., \& Ambos, B. 2010. The effect of quantity, quality, and timing of headquarters-initiated knowledge flows on subsidiary performance. Management International Review, 50(4): 493-511.

van Wijk, R., Jansen, J. J. P., \& Lyles, M. A. 2008. Inter- and Intra-Organizational Knowledge Transfer: A Meta-Analytic Review and Assessment of its Antecedents and Consequences. Journal of Management Studies, 45(4): 830-853.

Yamin, M., Tsai, H. J., \& Holm, U. 2011. The performance effects of headquarters' involvement in lateral innovation transfers in multinational corporations. Management International Review, 51(2): 157-178.

Olof Lindahl (olof.lindahl@fek.uu.se) teaches and does research as part of the IB Group at the Department of Business Studies, Uppsala University, in Sweden. His research is primarily concerned with intraMNC capability transfers, reshoring, and the role of headquarters in value-creation and innovation in the MNC. 